\title{
ARTICLE
}

\section{Psychological distress in the 5-year period after predictive testing for Huntington's disease}

\author{
Marleen Decruyenaere*,1, Gerry Evers-Kiebooms ${ }^{1}$, Trees Cloostermans ${ }^{1}$, Andrea Boogaerts ${ }^{1}$, \\ Koen Demyttenaere ${ }^{2}$, René Dom ${ }^{3}$ and Jean Pierre Fryns ${ }^{4}$
}

\author{
${ }^{1}$ Psychosocial Genetics Unit, University of Leuven, Herestraat 49, 3000 Leuven, Belgium; ${ }^{2}$ Department of Psychiatry, \\ University of Leuven, Herestraat 49, 3000 Leuven, Belgium; ${ }^{3}$ Department of Neurology, University of Leuven, \\ Herestraat 49, 3000 Leuven, Belgium; ${ }^{4}$ Center for Human Genetics, University of Leuven, Herestraat 49, 3000 \\ Leuven, Belgium
}

The paper reports on a 5-year longitudinal study on psychological distress after predictive testing for Huntington's disease (HD) and on correlates of post-test distress. Psychometric tests and questionnaires were used. The tested persons were invited to participate in the follow-up study; the uptake rate was 75\% (24 carriers, 33 non-carriers). Three time points were included: baseline, 1 year and 5 years posttest. Five years after the test, mean distress scores of both carriers and non-carriers were within the normal range. Carriers did not differ from non-carriers with regard to mean general distress. Compared to non-carriers, however, carriers had significantly less positive feelings $(P<0.001)$ and were more consciously avoiding HD-related situations and thoughts $(P<0.01)$. These findings reflect the carriers' conscious and unconscious attempt to escape from pessimism and to minimise negative consequences of the test result. Psychological distress 5 years post-test was significantly associated with ego-strength $(P<\mathbf{0 . 0 5}$ to $P<\mathbf{0 . 0 0 1})$. Except for intrusion and avoidance, distress was also associated with test motivation $(P<0.05$ to $P<0.01)$. Compared with baseline level, mean depression, general and specific anxiety had significantly decreased 1 year and 5 years post-test $(P<0.05$ to 0.01$)$. This evolution was independent of the test result. However, based on test motivation, a subgroup of tested persons having long lasting psychological distress could be identified, also irrespective of test result. Persons who asked the test to get rid of the uncertainty, without being able to specify implications for substantial life areas, had more psychological distress before and after the test than those who wanted the test for specific reasons $(P<0.001$ to $P<\mathbf{0 . 0 0 0 1})$. Moreover, the pattern of post-test anxiety differed over time, depending on the test motivation $(P<0.05)$. The findings suggest that pre- and post-test counselling should pay special attention to persons with lower ego-strength and with an unspecified test motivation, because they are at higher risk for long-term psychological distress, independently of the test result. European Journal of Human Genetics (2003) 11, 30-38. doi:10.1038/sj.ejhg.5200913

Keywords: Huntington's disease; predictive DNA-testing; psychological impact

\section{Introduction}

The psychological impact of predictive genetic testing for Huntington's disease (HD) has been evaluated through

\footnotetext{
*Correspondence: M Decruyenaere; Psychosocial Genetics Unit, U.Z. Gasthuisberg, Herestraat 49, B - 3000 Leuven (Belgium).

Tel: 32 - 16 - 3458 74; Fax: 32 - 16 - 3460 44;

E-mail: marleen.decruyenaere@med.kuleuven.ac.be

Received 3 July 2002; revised 12 September 2002; accepted 2 October 2002
}

qualitative and quantitative outcome studies. Several recent reviews on this topic have been published. ${ }^{1-3}$ All studies reported a low rate of severe psychiatric reactions. A world-wide survey ${ }^{4}$ revealed that psychiatric hospitalisation, suicide attempts and suicides were exceptional $(0.97 \%)$ after predictive testing. The follow-up studies showed that about 10 to $15 \%$ of both carriers and noncarriers experienced some psychological problems, including psychological burden, a period of depression, 
hopelessness about the future, concern about the children or (survival) guilt. ${ }^{1-3}$ Several hypotheses have been formulated to explain the low incidence of post-test problems: the pre- and post-test counselling of the participants, their mental resourcefulness and/or their coping strategies to deal with the negative consequences of the test result. ${ }^{1-6}$

Three observations concerning psychological functioning in the context of predictive testing have been long established. ${ }^{1-3}$ First, test participants are a self-selected subgroup with relatively good psychological resources. Second, post-test emotional distress is rarely associated with test result. And third, pre-test distress is a better predictor of post-test distress than test result. A higher level of depression and anxiety may be caused by a lower ego-strength and by less effective strategies to cope with stressful situations. ${ }^{7}$ This has been confirmed in a 1-year follow up study of predictive testing for HD. ${ }^{8}$

Several authors ${ }^{6,9,10}$ observed that some test applicants have unrealistic expectations regarding the test result. They use the risk of $\mathrm{HD}$ as an excuse for not facing the numerous uncertainties in life and expect that the test result in itself will solve their problems and uncertainties. Other test participants mainly want the test to help them in making decisions about family planning, to inform their grown children about their risk, or to make decisions on other matters. These persons seem to need the test to take specific actions. Compared to those who only want the test to 'get rid of the uncertainty', these persons have more clear expectations concerning the impact of the test.

The present paper reports on a 5-year longitudinal study of predictive testing for HD. The first aim of the paper is to assess general and specific distress in carriers and non-carriers, 5 years post-test. The second aim is to identify the role of ego-strength, test result and motives for testing in psychological distress 5 years post-test. The third aim is to assess the evolution over time of psychological distress, as a function of (a) test result and (b) test motivation. So far, the association of psychological distress with test motivation has not been investigated yet. We included three points of time: baseline, 1 year and 5 years post-test.

\section{Methods}

In Belgium, predictive testing for $\mathrm{HD}$ has been available as a clinical service since November 1987. Pre-test counselling and long-term emotional support have been provided by the predictive testing team. Psychological research is embedded in this clinical service which includes systematic follow-up sessions. ${ }^{11}$ This paper presents a selection of the findings of the 5-year follow-up study.

\section{Measures}

General and specific anxiety The trait-and the state-scale of the Spielberger's State Trait Anxiety Inventory ${ }^{12,13}$ (STAI) were used to measure general and specific anxiety.
Level of depression We used the Beck Depression Inventory ${ }^{14,15}$ (BDI) to assess the depression level.

Global dysfunctioning The Symptom Checklist ${ }^{16,17}$ (SCL90) assessed general psychological complaints and health status. Because of the high correlation among the eight subscales, we only used the total score in our analyses.

Intrusion and avoidance The degree of subjective impact of HD was measured with the Impact of Event Scale ${ }^{18}$ (IES). The IES consists of two scales: (a) intrusion (intrusively experienced ideas, feelings and thoughts about HD; seven items; score range: 0 to 35), and (b) avoidance (consciously recognised avoidance of certain ideas, feelings or situations; eight items; score range: 0 to 40 ).

Result-specific feelings The Health Orientation Scale ${ }^{19}$ (HOS) was used to assess the feelings associated with the test result. It consists of 12 bipolar five-point scales (badgood, afraid-unafraid, not guilty-guilty, ashamedunashamed, strong-weak, shocked-relieved, sad-happy, unmarked-marked, unable-able, pleased-angry, inactiveactive, sick-healthy). The scores range from 12 to 60 .

Ego-strength This was assessed with the Ego-strength scale of the Minnesota Multiphasic Personality Inventory. ${ }^{20,21}$

Motives for testing The participants' motives for testing have been extensively discussed during the pretest counselling. During the pretest phase, we could categorise the test participants into two groups: (1) persons who asked for the test because they can not live with the uncertainty about their risk, without being able to specify implications for their life (= 'unspecified' motives) and (2) those who wanted the test for specific purposes, such as family planning, informing the adult children about their risk status, making decisions about career or relationship,... (= 'specified' motives). Some persons of this group mentioned that they also wanted the test to get rid of the uncertainty. However, the essential difference with the first group is that the latter group has concrete ideas about expected changes or about future actions after the test.

Only the BDI, the STAI and the Ego-Strength-scale have been administered at the three points of time: before, 1 year and 5 years after the test.

\section{Participants}

In the period November 1987 - November 1995, 90 Flemish-speaking individuals with an affected parent had received a test result (33 carriers, 56 non-carriers, one equivocal result). In the period 1993-2000, these persons and their partners were invited to participate in a 5-year follow-up study; the person with the equivocal result was not included in the study. We only present the findings for the tested persons. 
Twenty-four of the 33 carriers responded to the 5-year follow-up (73\% response). Given the large number of non-carriers, only persons who received their result before November 1994 (43 non-carriers) were asked to participate in the study. Thirty-three of them agreed $(77 \%$ response rate). Most non-participation was due to lack of interest in follow-up counselling. The proportion of persons lost at the 5 year follow-up was 5/17 (29\%) among male carriers, 4/16 (25\%) among female carriers, 6/14 (43\%) among male non-carriers and 4/29 (14\%) among female non-carriers.

Overall, 57 persons participated in the study; 17 of them were tested with linkage analysis (five carriers, 12 noncarriers). During the follow-up contact, we had doubts about minor symptoms in six carriers; this doubt was also expressed by one of them.

\section{Statistical analyses}

Small samples and categorical variables were analysed with non-parametric tests. Differences between continuous variables were analysed using $t$-tests. The role of ego-strength, test result and test motivation in psychological distress 5 years post-test was assessed using multiple regression analysis. The coefficient of determination $\left(R^{2}\right)$ is the proportion of variance in the dependent variable explained by the independent variables. $R^{2}$ is independent of the order in which the variables are entered in the model. The adjusted $R^{2}$ is adjusted for number of predictors and sample size. The evolution over time of mean distress scores was assessed using multivariate analyses of variance for repeated measures. The Avoidance- and the Intrusion-scale of the IES and the BDI were not normally distributed. Therefore, raw scores of these three scales were square root transformed.

The statistical package used was SAS (Statistical Analysis Software). ${ }^{22}$

\section{Results}

Baseline socio-demographic variables

Table 1 presents baseline socio-demographic data for participants in the study $(n=57)$ and for the group lost to follow-up $(n=19)$. Except for sex, the differences between carriers and non-carriers in the group of participants were not statistically significant. The proportion of women in the group of non-carriers was significantly larger than the proportion of women in the carrier group.

The group of persons lost at the 5-year follow-up did not significantly differ from the participants in the study with regard to baseline socio-demographic data.

\section{Baseline psychological characteristics}

Carriers and non-carriers did not significantly differ with regard to baseline level of depression, general and specific anxiety, ego-strength and coping strategies. Moreover, the baseline psychological characteristics of the dropout group did not significantly differ from the participants' characteristics.
General and specific distress in tested persons, 5 years post-test

Table 2 presents the means for the distress measures in tested persons, 5 years post-test. The mean scores for both carriers and non-carriers were within the normal range. Carriers had a significantly higher mean score for avoidance (IES) and had significantly more negative feelings about their test result (HOS) than non-carriers.

Additionally, we tested whether the group of possibly affected carriers $(n=6)$ differed from the group without symptoms. The differences in psychological distress were not statistically significant.

\section{Role of ego-strength, test result and test motivation in psychological distress}

Test participants mentioned several motives for asking for the test: the uncertainty in their life (84\%), family planning (46\%), informing their children about their risk status (28\%) and other considerations (relationship, finances, studies, career; 9\%). In the pre-test period, we had categorised the test applicants in two groups, after an in-depth discussion of their test motivation: (1) those asking for the test because of the uncertainty, without being able to express expectations about specific changes after the test ('unspecified' motives; $n=14$; mean age $=36.8 ; \mathrm{SD}=8.7 ; 7$ carriers), and (2) those who could specify post-test implications or planned actions ('specified' motives; $n=43$; mean age $=36.4 ; \mathrm{SD}=10.2 ; 17$ carriers).

Table 3 presents the results of the multiple regression analysis. The standardised beta coefficient reflects the unique contribution of the independent variable to the dependent variable (after controlling for the other two variables). The unique contribution of ego-strength was significant for all distress variables. The contribution of test result was only significant for avoidance and for resultspecific feelings. The unique contribution of test motivation was significant for all distress variables, except for intrusion and avoidance.

Additionally, we investigated whether having minor symptoms had a predictive value for post-test distress. We found a small but significant unique contribution for result-specific feelings $\left(P<0.05\right.$; adj. $\left.R^{2}: 0.45\right)$, but not for the other distress measures.

\section{Evolution over time of depression, anxiety and ego-} strength, as a function of test result

Table 4 presents the means for depression level, general and specific anxiety and ego-strength over time (see also Figure 1 ). The analysis of repeated measures showed a significant effect of time for depression, general and specific anxiety. No significant differences were found between carriers and non-carriers.

Depression (Figure 1a) The decrease from baseline to 1 year post-test $(F=7.50 ; \mathrm{df}=1,48 ; P<0.01)$ and from baseline to 5 years post-test $(F=5.21 ; \mathrm{df}=1,48 ; P<0.05)$ was signifi- 
Table 1 Baseline socio-demographic characteristics of the follow-up group $(n=57)$ compared with the persons lost to followup $(n=19)$

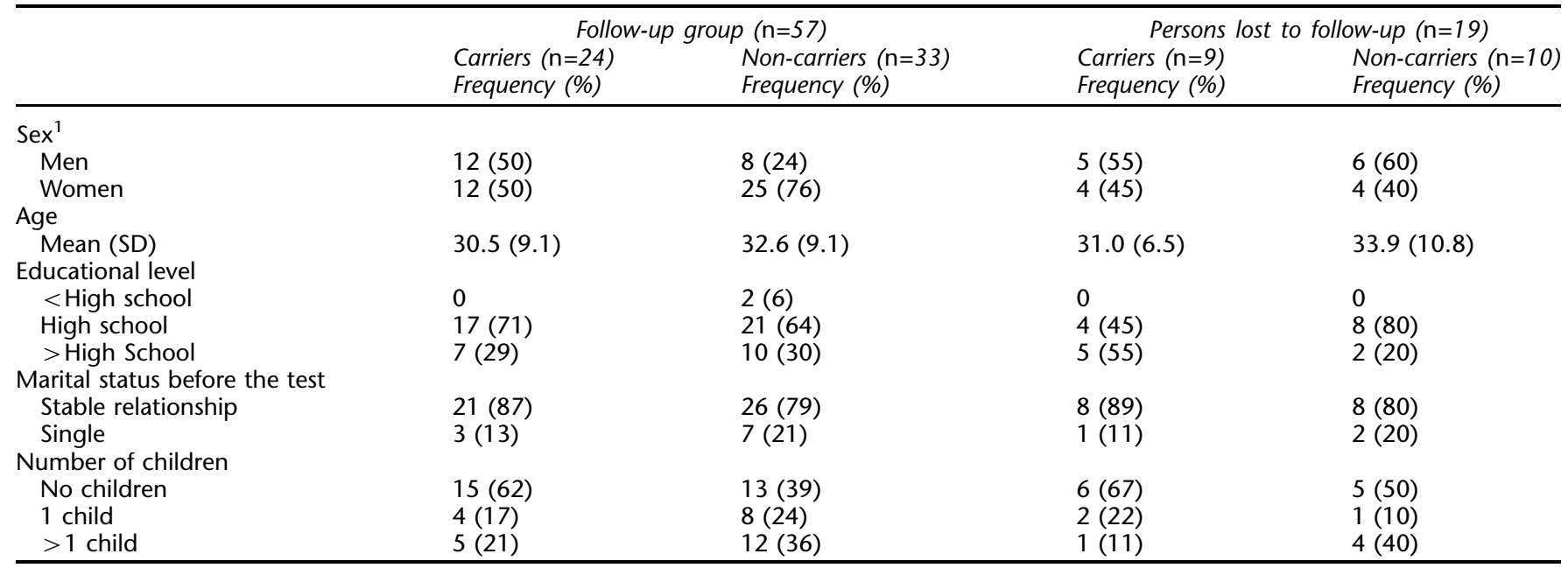

${ }^{1}$ Sex: Pair-wise comparison within the group of participants $(n=57)$ : The proportion of women was significantly larger in the group of noncarriers than in the carrier group (Chi-sq=4.05; $P=0.04$ ).

Table 2 General and specific distress in the follow-up group, 5 years post-test

\begin{tabular}{|c|c|c|c|c|c|}
\hline & & $\begin{array}{l}\text { Carriers } \\
\mathrm{n}=24\end{array}$ & $\begin{array}{l}\text { Non-carriers } \\
\mathrm{n}=33\end{array}$ & $t$ & $P$ \\
\hline \multicolumn{6}{|l|}{ General distress } \\
\hline Depression & $M$ & 4.1 & 4.1 & -0.34 & ns \\
\hline \multirow[t]{2}{*}{ General Anxiety (1) } & $\mathrm{M}$ & 34.9 & 35.0 & -0.03 & ns \\
\hline & SD & 10.7 & 10.0 & & \\
\hline $\begin{array}{l}\text { Global dysfunctioning } \\
\text { (1) }\end{array}$ & $\mathrm{M}$ & 123 & 132 & -0.80 & ns \\
\hline \multicolumn{6}{|l|}{ Specific distress } \\
\hline \multirow{2}{*}{ Specific Anxiety } & M & 35.7 & 33.2 & 0.95 & ns \\
\hline & SD & 9.8 & 10.3 & & \\
\hline \multirow[t]{2}{*}{ Intrusion } & M & 9.5 & 7.1 & 1.67 & ns \\
\hline & SD & 7.0 & 7.9 & & \\
\hline \multirow[t]{2}{*}{ Avoidance } & M & 10.8 & 6.0 & 2.69 & $<0.01$ \\
\hline & SD & 8.0 & 6.8 & & \\
\hline
\end{tabular}

${ }^{1}$ General Anxiety: Carriers $n=23 /$ Non-carriers $n=33$; Global dysfunctioning: Carriers $n=21 /$ Non-carriers $n=32 .{ }^{2}$ HOS: Health Orientation Scale (Min.=12/Max.=60; Higher scores mean more favourable feelings).

cant. The change of mean depression scores from 1 to 5 years after the test was not significant.

General anxiety (Figure 1b) The decrease from baseline to 5 years post-test was significant $(F=9.55 ; \mathrm{df}=1,47 ; P<0.01)$. The decreases from baseline to 1 year post-test and from 1 to 5 years post-test were not significant.

Specific anxiety (Figure 1c) The decrease from baseline to 1 year post-test $(F=14.23 ; \mathrm{df}=1,48 ; P<0.001)$ and from baseline to 5 years post-test $(F=8.42 ; \mathrm{df}=1,48 ; P<0.01)$ was significant. The increase from 1 to 5 years post-test was not significant.
Ego-strength (Figure 1d) Mean ego-strength scores did not significantly change over time.

Evolution over time of depression, anxiety and egostrength, as a function of motives

We performed a multivariate analysis for repeated measures, with time as the within-subject factor, and test motivation as the between-subject factor (Figure 2). For the three distress measures, we found a significant difference $(P<0.001)$ between the two motivation-groups.

Depression (Figure 2a) The decrease of mean depression from baseline to 1 year post-test was significant $(F=8.49$; 
Table 3 Results of the multiple regression analysis with distress 5 years post-test as dependent variables and Ego-strength, test result and test motivation as predictors: standardised beta's for the predictors and adjusted $R^{2}$ for each dependent variable

\begin{tabular}{|c|c|c|c|c|}
\hline Dependent variables & Ego-Strength & $\begin{array}{c}\text { Standardised } \beta \text { for independent variables } \\
\text { Test Result (1) }\end{array}$ & Motives (2) & Adjusted $R^{2}$ \\
\hline \multicolumn{5}{|l|}{ General measures } \\
\hline Depression & $-0.47^{* * *}$ & 0.10 & $-0.26^{\star}$ & $0.34^{* * *}$ \\
\hline Global dysfunctioning $\left({ }^{3}\right)$ & $-0.54^{\star * *}$ & 0.09 & $-0.24^{\star}$ & $0.40^{* * *}$ \\
\hline \multicolumn{5}{|l|}{ Specific measures } \\
\hline Specific Anxiety & $-0.27^{\star}$ & -0.11 & $-0.38^{\star *}$ & $0.25^{\star * *}$ \\
\hline Result-sp.feelings $\left({ }^{4}\right)$ & $0.25^{*}$ & $0.55^{\star \star \star}$ & $0.24^{*}$ & $0.41^{* * *}$ \\
\hline
\end{tabular}

(1) Test result: 1=Carrier; 2=Non-carrier. (2) Test motivation: 1=Unspecified; 2=Specified. (3) General anxiety: Carriers $n=23 /$ Non-carriers $n=33$; global dysfunctioning: Carriers $n=21 /$ Non-carriers $n=32$. (4) HOS: Health Orientation Scale: Higher scores mean more positive feelings. ${ }^{* \star *}: P<0.001 ;{ }^{* *}: P<0.01 ;{ }^{*}: P<0.05$

$\mathrm{df}=1,48 ; P<0.01)$. The changes from baseline to 5 years post-test and from 1 to 5 years post-test were not significant.

General anxiety (Figure $2 \boldsymbol{b}$ ) Here, the evolution over time was different for the two motivation-groups. In the group with unspecified motives, general anxiety did not significantly change over time. For those with a specified motivation, general anxiety significantly decreased from baseline to 5 years post-test $(t=4.33 ; P<0.0001)$ and from 1 to 5 years post-test $(t=2.16 ; P<0.05)$.

Specific anxiety (Figure 2c) Here too, the evolution over time was different for the two motivation-groups. First, specific anxiety significantly decreased from baseline to 1 year follow-up for both groups $(t=3.18 ; P<0.01$ for the specified motives-group; $t=2.47 ; P<0.05$ for the unspecified motives-group). However, for those with unspecified motives, mean specific anxiety significantly increased from 1 to 5 years post-test $(t=-2.48 ; P<0.05)$. For those with specific motives, on the contrary, mean specific anxiety remained at the same level from 1 to 5 years post-test; the decrease from baseline to 5 years post-test was significant $(t=4.17 ; P<0.001)$.

Ego-strength (Figure 2d) Mean ego-strength for the unspecified motives-group was lower than the mean for the specified motives-group, but the difference was only marginally significant $(P=0.08)$.

In order to study the potential interacting effect of test result and motivation, we included test result as an additional between-subject factor. The effect of test motivation remained significant $(P<0.001)$ and we found no significant interaction between test result and test motivation.

\section{Discussion}

This study assessed psychological distress in mutationcarriers and non-carriers, 5 years post-test. Our results confirm previous findings. ${ }^{1-6}$ Mean distress scores for both carriers and non-carriers were within the normal range. Compared to non-carriers, carriers had significantly more negative feelings about their test result and were significantly more avoiding HD-related situations and thoughts. This avoidance behaviour of carriers can be considered as a beneficial, self-protective choice to escape from pessimism and negative consequences of the test result. Avoidance is a sound strategy in order to keep stress and anxiety at a manageable level in situations where preventability and controllability of the threat are low. ${ }^{23,24}$ This defensive avoidance does not necessarily hinder health-related behaviour. $^{25}$ An example of relevant health-related behaviour in this context is the use of prenatal testing.

Our study further confirmed the previously reported finding that pre-test ego-strength is a strong predictor of posttest distress. ${ }^{8}$ A new finding is that test motivation also has a strong predictive value with respect to long-term distress, independently of ego-strength and test result.

Moreover we assessed the evolution over time of psychological distress and ego-strength as a function of test result and test motivation. For the total group of participants, mean distress had significantly decreased over the long term, while mean ego-strength remained high over time. This evolution was the same for carriers and non-carriers. However, it was different for the two motivation-groups. Based on test motivation, we could delineate a subgroup of tested persons in which psychological distress reappeared after some years or even remained high after testing. Persons who asked the test to get rid of the uncertainty, without being able to specify concrete future implications of the test, were significantly more distressed before and after the test than those who wanted the test for specified reasons. The group with unspecified reasons moreover tended to have lower levels of ego-strength. These findings were independent of test result. It is clear that for this group of test participants, carriers as well as non-carriers, the test result had not brought relief in the long term, 
a
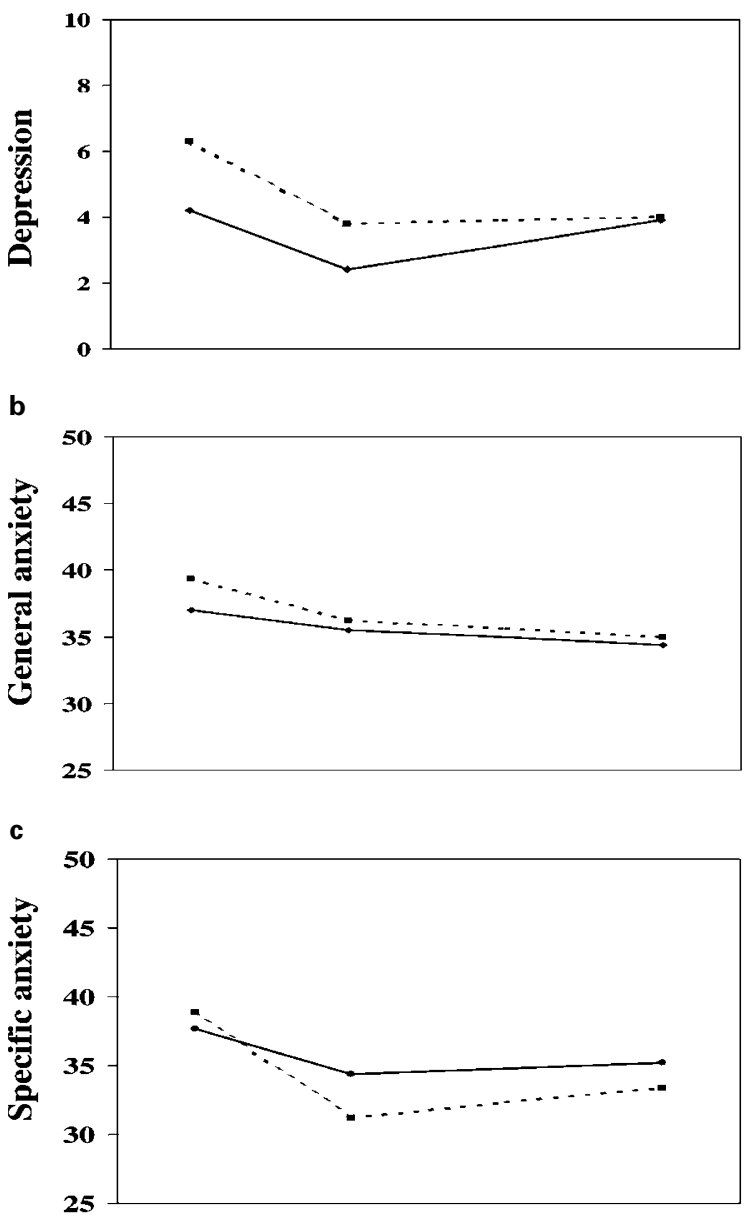

d

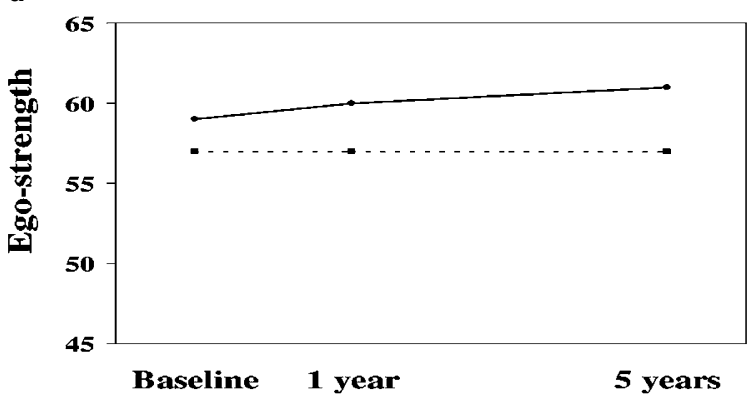

Result — Carrier

----- Non-carrier

Test result : $F=.47 ; d f=1,48 ; n . s$

Time $^{\circ}: F=4.4 ; d f=2,47 ; p<.05$

Time $X$ Result ${ }^{\circ}: F=.03 ; \mathrm{df}=2,47 ;$ n.s.

Curvilinear effect : $F=6.04 ; d f=1,48 ; p<.05$
Test result : $F=.25 ; \mathrm{df}=1,47 ;$ n.s.

Time $^{\circ}$ : F=4.7; $d f=2,46 ; p<.05$

Time $X$ Result ${ }^{\circ}: F=.29 ; d f=2,46 ;$ n.s.

Curvilinear effect : $F=1.39 ; \mathrm{df}=1,47 ;$ n.s.
Test result : $F=.43 ; d f=1,48 ; n . s$

Time $^{\circ}: \mathrm{F}=7.7 ; \mathrm{df}=2,47 ; \mathrm{p}<.01$

Time $X$ Result ${ }^{\circ}: F=1.2 ; d f=2,47 ;$ n.s.

Curvilinear effect : $F=12.2 ; d f=1,48 ; p<.01$

Test result : $F=1.17 ; \mathrm{df}=1,47 ;$ n.s.

Time $^{\circ}: F=.22 ; d f=2,46 ;$ n.s.

Time $X$ Result $^{\circ}: F=.28 ; d f=2,46 ;$ n.s.

Curvilinear effect : $\mathrm{F}=.13 ; \mathrm{df}=1,47 ;$ n.s.

Figure 1 Evolution over time of (a) mean depression level, (b) mean general anxiety, (c) mean specific anxiety and (d) mean egostrength, as a function of test result.

witness the return to baseline level of psychological distress. For those who wanted the test for well-defined purposes, on the contrary, psychological distress had significantly decreased 5 years post-test. Compared to the group with unspecified motives, this group clearly benefited more of a predictive test, not only because of the lower anxiety 5 years post-test, but probably also because they eventually could take action, based on a favourable or unfavourable test result.
The mechanism underlying the association between test motivation and distress still has to be ascertained. Vague test expectations may cause psychological distress, and vice versa, psychological distress may be a barrier to look at the future and to deal with problems. Additionally, both distress and type of test motivation may be influenced by other variables, such as style of coping with threatening information $^{26,27}$ or past and/or current experiences with HD in the family. ${ }^{28}$ 
a

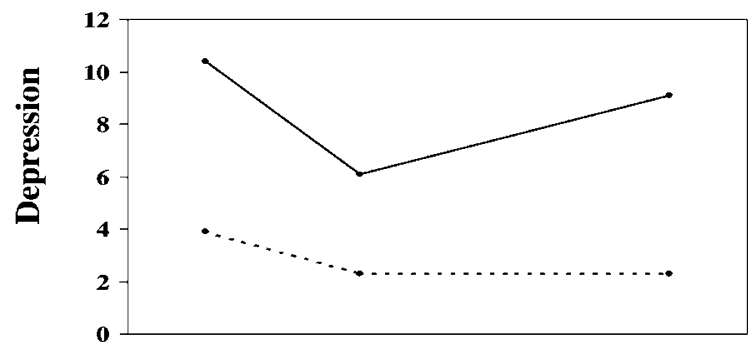

b

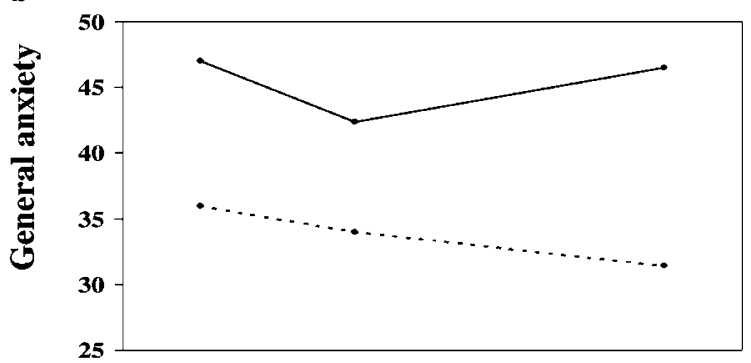

c

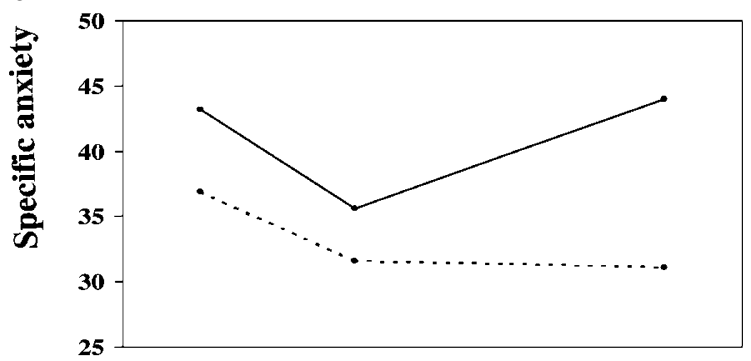

d

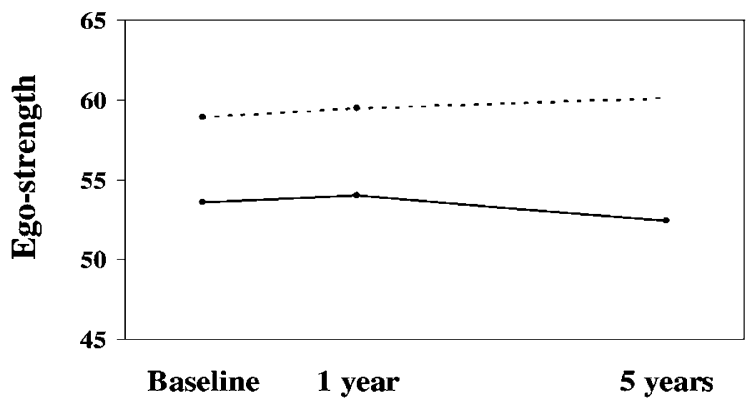

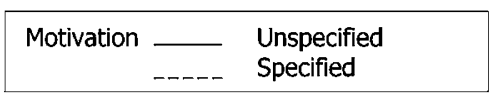

Motivation : $F=18.8 ; \mathrm{df}=1,48 ; \mathrm{p}<.0001$

Time $^{\circ}: \mathrm{F}=4.2 ; \mathrm{df}=2,47 ; \mathrm{p}<.05$

Time $X$ Motivation $^{\circ}: F=1.5 ; \mathrm{df}=2,47 ; \mathrm{ns}$

Curvilinear effect : $F=7.9 ; d f=1,48 ; p<.01$
Motivation : $F=23.7 ; d f=1,47 ; p<.0001$

Time $^{\circ}: \mathrm{F}=2.1 ; \mathrm{df}=2,46 ; \mathrm{ns}$

Time $X$ Motivation $^{\circ}: F=3.5 ; \mathrm{df}=2,46 ; p<.05$

Curvilinear effect : $\mathrm{F}=2.7 ; \mathrm{df}=1,47$; ns
Motivation : $\mathrm{F}=15.3 ; \mathrm{df}=1,48 ; \mathrm{p}<.001$

Time $^{\circ}: \mathrm{F}=7.1 ; \mathrm{df}=2,47 ; \mathrm{p}<.01$

Time $X$ Motivation $^{\circ}: \mathrm{F}=4.9 ; \mathrm{df}=2,47 ; \mathrm{p}<.05$

Curvilinear effect : $F=14.5 ; d f=1,48 ; p<.01$
Motivation : $F=3.26 ; d f=1,47$; $n s \quad(p=.08)$

Time $^{\circ}: \mathrm{F}=.07 ; \mathrm{df}=2,46 ; \mathrm{ns}$

Time $X$ Motivation $^{\circ}: F=.47 ; \mathrm{df}=2,46 ; \mathrm{ns}$

Curvilinear effect : $F=.11 ; \mathrm{df}=1,47 ; \mathrm{ns}$

Figure 2 Evolution over time of (a) mean depression level, (b) mean general anxiety, (c) mean specific anxiety and (d) mean egostrength, as a function of test motivation.

Another question is how tested carriers will react emotionally when the first symptoms of HD appear. They may experience more distress or the denial-avoidance may have increased. In this study, no significant differences were found between the six possibly affected carriers and the other carriers. However, after controlling for ego-strength and test motivation, the possibly affected carriers had significantly more positive feelings towards their test result than the other carriers. This may reflect an unconscious denial of the onset of HD. However, it is clear that a sample of six persons is too small to investigate the effect of the disease onset on long-term distress. Moreover, since this was not the aim of our study, we did not include an objective criterion to confirm the presence of first symptoms.

About one quarter of the initial group of tested persons was lost at the 5-year follow-up, mostly due to lack of interest in follow-up contact. The proportion of nonparticipation was largest among male non-carriers and 
Table 4 Mean scores for depression level, general and specific anxiety and ego-strength of carriers and noncarriers over three points of time: before the test, one year and 5 years post-test

\begin{tabular}{lllll}
\hline \multirow{2}{*}{ Variables } & Result (1) & Baseline & \multicolumn{3}{l}{ Means $($ year } & 5 year \\
\hline Depression & $\mathrm{C}(n=21)$ & $4.2(4.2)$ & $2.4(2.6)$ & $3.9(6.1)$ \\
& $\mathrm{NC}(n=29)$ & $6.3(8.6)$ & $3.8(6.1)$ & $3.9(4.7)$ \\
General Anxiety & $\mathrm{C}(n=20)$ & $37.1(7.6)$ & $35.4(10.4)$ & $34.4(11.1)$ \\
& $\mathrm{NC}(n=29)$ & $39.4(11.0)$ & $36.2(9.4)$ & $35.0(9.9)$ \\
Specific Anxiety & $\mathrm{C}(n=21)$ & $37.7(9.0)$ & $34.4(9.1)$ & $35.2(10.3)$ \\
& $\mathrm{NC}(n=29)$ & $38.9(9.0)$ & $31.2(6.9)$ & $33.4(9.2)$ \\
Eg-Strength & $\mathrm{C}(n=20)$ & $59.1(7.9)$ & $60.1(8.3)$ & $60.9(9.9)$ \\
& $\mathrm{NC}(n=29)$ & $56.8(13.1)$ & $57.0(14.3)$ & $56.7(10.7)$ \\
\hline
\end{tabular}

(1) For the 1 year follow-up, seven persons (three carriers and four non-carriers) were missing because they had their 1 year follow-up in another centre (Ghent, Antwerp). The baseline and 5 year posttest distress scores of these seven persons did not significantly differ from the distress scores of the other test particpants. For Egostrength, one additional subject was missing at the 1-year assessment.

smallest among female non-carriers. It would be interesting to know more about the long-term psychological functioning of the persons lost at follow-up; this may lead to suggestions for guidance and support. Ethical considerations however impede this kind of research: we have to respect the reluctance of this group against being contacted.

Another remark concerns the male/female ratio in the group of participants. An overrepresentation of women opting for predictive testing has been reported. ${ }^{5,6}$ This has been explained by the assumption that women usually act as genetic housekeepers. ${ }^{29}$ In our group of tested persons, the ratio female/male in non-carriers proved to be larger than in carriers. ${ }^{8}$ Finally, for a discussion of post-test reproductive decisions, we refer to the results of the European collaborative study ${ }^{30}$ on reproductive decisions after predictive testing.

The study has clear implications for pre- and post-test counselling. Counselling should pay special attention to persons with lower ego-strength and with an unspecified test motivation. An in-depth discussion of the participant's test motivation should be an essential component of pretest counselling. This is a complex topic because test applicants are not always aware of their conscious and unconscious motives and expectations. Getting insight into the participants' motives requires considerable expertise of the counsellor. A helpful method is the development of 'scenarios'. ${ }^{31}$ We ask test participants to explore possible outcomes of predictive testing and to anticipate how they would react. The expression of beliefs, emotions and expectations is stimulated, which allows test applicants to get more insight into their test motivation. In most cases, indepth exploration of the motivation allows to make future actions and expectations more concrete. However, in some cases, test participants are not able to specify concrete implications for their life. Their test request is more emotionally laden, they have a lower ego-strength and they seem to have a low awareness of motives and unconscious factors that play a part. In these cases, extra attention should be paid to prepare these persons for the emotional implications of a test result. Supporting and raising their self-esteem and enhancing their feelings of personal control are key components of this preparation phase. If necessary, additional counselling should be offered.

Follow-up counselling should also pay special attention to these persons with unspecified motives because they are at higher risk for long-term psychological distress. Post-test counselling should reinforce their sense of competence, raise their personal control over life and encourage them to actively cope with problems. In some cases, psychotherapy may be needed. Based on our experiences with $\mathrm{HD}$, we recommend a contextual approach in which the family dynamics are taken into account ${ }^{28,32}$ and in which active problem-solving strategies are stimulated. ${ }^{33}$

\section{Acknowledgements}

We express special gratitude to the participants in this study. We also want to thank Professor A De Paepe (Ghent) and Professor J Dumon (Antwerp) for their permission to include testees from their centre.

\section{References}

1 Evers-Kiebooms G, Decruyenaere M: Predictive testing for Huntington's disease: a challenge for persons at risk and for professionals. Patient Educ Counsel 1998; 35: 15-26.

2 Broadstock M, Michie S, Marteau T: Psychological consequences of predictive genetic testing: a systematic review. Eur J Hum Gen 2000; 8: 731-738.

3 Duisterhof M, Trijsburg RW, Niermeijer MF, Roos RAC, Tibben A: Psychological studies in Huntington's disease: making up the balance. J Med Genet 2001; 38: 852-861.

4 Almqvist EW, Bloch M, Brinkman R, Craufurd D, Hayden M on behalf of an international HD collaborative group: A worldwide assessment of the frequency of suicide, suicide attempts, or psychiatric hospitalization after predictive testing for HD. Am J Hum Genet 1999; 64: 1293-1304.

5 Tibben A, Timman R, Bannink EC, Duivenvoorden HJ: Three year follow-up after presymptomatic testing for HD in tested individuals and partners. Health Psych 1997; 16: 20-35.

6 Codori AM, Brandt J: Psychological costs and benefits of predictive testing for Huntington's disease. Am J Med Gen 1994; 54: $174-184$.

7 Lazarus RS, Folkman S: Stress, appraisal and coping. New York: Springer 1984

8 Decruyenaere M, Evers-Kiebooms G, Boogaerts A et al: Prediction of psychological functioning one year after the predictive test for Huntington's disease and impact of the test result on reproductive decision making. J Med Gen 1996; 33: 737-743.

9 Wexler N: The Tiresias complex: Huntington's disease as a paradigm of testing for late-onset disorders. The FASEB Journal 1992; 6: $2820-2825$

10 Tibben A, Duivenvoorden HJ, Vegter-Van der Vlis $\mathrm{M}$ et al: Presymptomatic DNA testing for Huntington disease: identifying the need for psychological intervention. Am J Med Genet 1993; 48: $137-144$. 
11 Decruyenaere M, Evers-Kiebooms G, Boogaerts A et al: Predictive testing for Huntington's disease: Risk perception, reasons for testing and psychological profile of test applicants. Genet Counsel 1995; 6: 1-13.

12 Spielberger CD, Gorsuch RL, Lushene RE: Manual for the State Trait Anxiety Inventory. Palo Alto: Consulting Psychologists Tests 1970.

13 Van der Ploeg HM, Defares PB, Spielberger CD: Handleiding bij de Zelfbeoordelingsvragenlijst: een Nederlandstalige bewerking van de Spielberger STAI. New York: Swets \& Zeitlinger 1980.

14 Beck AT, Steer RA, Garbin M: Psychometric properties of the Beck Depression Inventory: twenty-five years of evaluation. Clin Psych Rev 1988; 8: 77-100.

15 Bouman TK, Luteijn F, Albertnagel FA, Van der ploeg FA: Enige ervaringen met de Beck Depression Inventory. Gedrag Tijdsch Psych 1985; 13: 13-24.

16 Derogatis L: SCL-90: Administration, scoring and procedures for the $R$ (evised) version. Baltimore: John Hopkins University School of Medicine 1977.

17 Arrindell WA, Ettema JHM: SCL-90: Handleiding bij een multidimensionele psychopathologie-indicator. Lisse: Swets Test Services 1986.

18 Horowitz M, Wilner N, Alvarez W: Impact of event scale: a measure of subjective stress. Psychosom Med 1979; 41: 209-218.

19 Wooldridge EQ, Murray RF: The health orientation scale: a measure of feelings about sickle cell trait. Social Biology 1988; 35: $123-136$.

20 Barron F: An ego-strength scale which predicts response to psychotherapy. J Cons Psych 1953; 17: $327-333$.

21 Graham JR: The MMPI. A practical guide. New York: Oxford University Press 1987.

22 Statistical Analysis Software, SAS Institute Inc., 1999.

23 Taylor SE, Brown JD: Illusion and well-being: a social psychological perspective on mental health. Psychol Bull 1988; 103: $193-$ 210.
24 Croyle RT, Sun Y, Louie DH: Psychological minimization of cholesterol test results: moderators of appraisal in college students and community residents. Health Psych 1993; 6: $503-$ 507.

25 Leventhal H, Cameron L: Behavioural theories and the problem of compliance. Patient Educ Counsel 1987; 10: 117-138.

26 Tercyak KP, Lerman C, Peshkin BN et al: Effects of coping style and BRCA1 and BRCA2 test results on anxiety among women participating in genetic counseling and testing for breast and ovarian cancer risk. Health Psych 2001; 20: 217-222.

27 Miller S, Brody DS, Summerton J: Styles of coping with threat: implications for health. J Person Social Psych 1988; 54: 142-148.

28 Demyttenaere K, Evers-Kiebooms G, Decruyenaere M: Pitfalls in counseling for predictive testing in Huntington disease. March of Dimes, Birth Defects 1992; 28: $105-112$.

29 Richards M: Families, kinships and genetics; in Marteau T, Richards M (eds) The troubled helix, social and psychological implications of the new human genetics. Cambridge University Press, 1996, pp 249-273.

30 Evers-Kiebooms G, Nys K, Harper P et al: Predictive DNA-testing for Huntington's disease and reproductive decision making: a European collaborative study. Eur J Hum Gen 2002; 10: 167-176.

31 Huys J, Evers-Kiebooms G, d'Ydewalle G: Decision making in the context of genetic risk: the use of scenarios. March of Dimes, Birth Defects 1992; 28: 17-20.

32 Boszormenyi-Nagy I, Ulrich D: Contextual Family Therapy; in Gurman A, Kniskern P (eds) Handbook of family therapy. New York, Brunner Mazel, 1980, pp 159-186.

33 Heim E: Coping-based intervention strategies. Patient Educ Counsel 1995; 26: $145-151$. 